\title{
Educação infantil e avaliação escolar: experiências das crianças com a linguagem
}

\section{Early childhood education and school assessment: children's experiences with language}

Renata Provetti Weffort Almeida, Doutora em Educação pela PUC/SP, pelo Programa Educação: História, Política, Sociedade. Tem como temas de interesse de pesquisa a Educação Infantil, infância e avaliação escolar. Atualmente é coordenadora assistente da Educação Infantil e $1^{\circ}$ ano do Ensino Fundamental do Colégio Vital Brazil.

Contato: renataweffort@gmail.com

\section{Resumo}

0 presente texto tem como objetivo descrever e analisar as experiências das crianças com a linguagem, por meio das avalições escolares. Os dados apresentados são parte de tese de doutorado defendida no ano de 2014. A investigação foi realizada por meio da análise das avaliações das crianças de duas escolas, uma pública e uma privada. Em cada uma das escolas pesquisadas foram selecionadas duas salas de aula, perfazendo um total de quatro salas. Nas duas escolas foram coletados e analisados os instrumentos que envolvem o processo de avaliação das crianças. A perspectiva teórica tem como referência os estudos dos pensadores da teoria crítica da sociedade, sobretudo os que tratam da formação e experiência. Tais conceitos contribuem para a compreensão dos processos pelos quais ocorre a formação do indivíduo - neste caso a formação das crianças - e as possibilidades de experiência oferecidas pela escola. Em linhas gerais, a conclusão da presente pesquisa é a de que, tendencialmente, as avaliações expressam uma perspectiva padronizada e predeterminada do desenvolvimento das crianças, em detrimento da possibilidade de experiências formativas que visem à reflexão e à formação. Desse modo, as atividades realizadas pelas crianças, mediadas pelos professores, 
apontam para o empobrecimento da experiência com a linguagem, pela redução do repertório linguístico, devido à priorização da realização de sondagens de escrita.

Palavras-chave: Educação Infantil, avaliação escolar, linguagem.

\begin{abstract}
This paper aims to describe and analyze children experiences with language through school evolution based on previous data presented in a doctorate degree defended in 2014. The research was conducted by analyzing children's evaluations from two different contexts, from a public and from a private school. A total of four groups were studied, two from each school. The assessment tools involved in the children's evaluation process were then collected and analyzed in both schools. The theoretical perspective is grounded in the study of critical theory thinkers of society, particularly those who take into account the issues of training and experience. These concepts contribute to the understanding of the processes that enable individual growth - in this case children's development - and the various possibilities of experience offered by schools. Generally speaking, the conclusion of this research is that evaluations tend to express a standardized and predetermined perspective of children's development to the detriment of the possibility of formative experiences focused on reflection and training. Thus, the activities carried out by children, mediated by teachers, point to the impoverishment of language experience due to the reduction of linguistic repertoires caused by the prioritization of writing surveys.

Keywords: Early childhood education, school assessment, language.
\end{abstract}

\title{
Introdução
}

Apesar do crescimento de determinações legais, os desafios para a conquista de uma Educação Infantil de qualidade ainda não foram superados, muitos sequer identificados. Dentre eles, identifica-se a avaliação escolar como um aspecto importante a ser pesquisado e debatido. Conforme definido por Rosemberg (2013), há uma distinção entre avaliação "na" e "da" Educação Infantil, ou seja, enquanto os documentos referentes à avaliação 
"na" Educação Infantil tratam daquela realizada dentro da escola, a avaliação "da" refere-se a instrumentos que aferem a qualidade da Educação Infantil. Portanto, a presente discussão trata sobre a avaliação na Educação Infantil.

Este texto apresenta parte dos resultados da pesquisa de doutorado realizada em duas escolas, uma pública e uma privada, da cidade de São Paulo. Para fins de organização da presente discussão, optou-se pelo seguinte recorte: como são avaliadas as experiências das crianças com a linguagem na escola. No que tange aos aspectos metodológicos, a investigação foi realizada por meio da análise das avaliações das crianças de duas escolas, uma pública e uma privada. Em cada uma das escolas pesquisadas foram selecionadas duas salas de aula, perfazendo um total de quatro salas. Nas duas escolas foram coletados e analisados os instrumentos que envolvem o processo de avaliação das crianças.

Embora seja uma tarefa permanente nas instituições escolares, tanto as escolas quanto os documentos oficiais sobre a Educação Infantil não oferecem aos professores elementos suficientes para o conhecimento e reflexão acerca da função que a avaliação desempenha na escola e na formação da criança. Desse modo, o proceder avaliativo parece ocorrer por meio da apropriação de um discurso pedagógico constituído com base na própria prática escolar, com suas transformações e necessidades sucessivas de adequações, nas políticas educacionais e, por fim, nos livros que circulam pelas escolas.

Em face desse entendimento, é de fundamental importância a compreensão dos modos de efetivação do trabalho pedagógico nessa modalidade escolar.

Se, por um lado, a avaliação escolar na Educação Infantil potencialmente pode contribuir para o processo formativo das crianças, apontando os melhores caminhos para sua formação e inserção qualificada e crítica na cultura, por outro, pode cumprir meramente a função burocrática, empobrecendo a própria experiência escolar, considerando o risco de as propostas serem moldadas para fins avaliativos. Daí a relação entre a avaliação e a experiência das crianças na escola.

Tomando como base a linguagem, considera-se, como elemento fundamental, que as escolas propiciem experiências com e por meio da linguagem, por intermédio das quais as crianças possam conviver com o diferente, cooperar, expor seus pontos de vista e refletir sobre as diversas situações com que se defrontam, como 
também aprendam, paulatinamente, a se colocar no lugar do outro em situações que se apresentam na realidade, tais como conflitos ou em situações de disputa, como as que surgem no faz de conta, com conteúdos da fantasia e da imaginação, em manifestações espontâneas.

0 professor tem fundamental importância nesse processo, visto que, além de desempenhar funções relativas à socialização primária, sua atuação mediadora das situações vividas pelas crianças, como uma figura de autoridade, possibilita, por meio de suas ações, a incorporação, por parte das crianças, de hábitos e condutas favoráveis ao convívio social - sem abandonar a transmissão do conhecimento -, exercendo, nas palavras de Adorno, uma autoridade esclarecida.

Desse modo, os padrões de conduta internalizados pelos indivíduos podem ser positivos no processo de formação dos indivíduos. Contudo, os mecanismos de coerção e de integração presentes em sociedades totalitárias ${ }^{1}$ podem desenvolver a submissão, a obediência e o medo. Assim sendo, a escola, como expressão da sociedade, por intermédio das relações que ali se estabelecem, pode operar em um duplo sentido: colaborar para a formação e inserção qualificada da criança na cultura ou operar no sentido de conformar seus alunos, de acordo com os ditames da sociedade.

\section{Referencial teórico}

A linguagem constitui-se em um elemento fundamental como mediação entre o indivíduo e a cultura. Por meio da linguagem, o indivíduo apreende os elementos da cultura, desenvolve sua capacidade de abstração e de formulação dos conceitos.

Apesar disso, a linguagem assume um caráter ambíguo, pela mediação e pelo imediatismo que assume na sociedade capitalista. Conforme foi discutido por Marcuse (1979), no texto 0 fechamento do universo da locução, a sociedade cria diversos recursos que têm por finalidade a manipulação e o controle dos indivíduos, dentre os quais o empobrecimento da linguagem. A linguagem perde sua capacidade de mediação à medida que a locução assume características unidimensionais².

Os elementos de autonomia, descoberta, demonstração e crítica recuam diante da designação, asserção e imitação. Elementos mágicos, autoritários e rituais invadem a palavra e a linguagem.
1. De acordo com a perspectiva adotada neste estudo, utiliza-se o termo sociedade totalitária, segundo Marcuse (1979, p.24), "em virtude do modo pelo qual organizou a sua base tecnológica, a sociedade industrial tende a tornar-se totalitária. Pois, 'totalitária' não é apenas uma coordenação política terrorista da sociedade, mas também uma coordenação técnico-econômica não terrorista que opera através da manipulação das necessidades por interesses adquiridos".

2. A falsa consciência ou consciência feliz produzida pela racionalidade tecnológica prevalecente, em que o indivíduo é levado a abrir mão da transformação por acreditar no existente que lhe é afirmado, cria um novo padrão de pensamento unidimensional "no qual as ideias, as aspirações e os objetivos que por seu conteúdo transcendem o universo estabelecido da palavra e da ação são repelidos ou reduzidos a termos desse universo. São redefinidos pela racionalidade do sistema dado e de sua extensão quantitativa" (MARCUSE, 1979, p.32) 
A locução é privada das mediações que são as etapas do processo de cognição e avaliação cognitiva. Os conceitos que compreendem os fatos, e desse modo transcendem estes, estão perdendo sua representação linguística autêntica. Sem tais mediações, a linguagem tende a expressar e a promover a identificação imediata da razão e do fato, da verdade e da verdade estabelecida, da essência e da existência, da coisa e da sua função. (MARCUSE, 1979, p.93).

Essa função imediata da linguagem reduz, ou impossibilita, a capacidade de reflexão, de abstração e de observação dos fatos por diferentes perspectivas, decorrente do empobrecimento da experiência. Adorno (2006), em debate registrado na coletânea Educação e Emancipação, sob o título "Educação - Pra quê?, em que discute os objetivos educacionais e a relação entre a teoria e a prática, ressalta que

[...] seria preciso estudar o que as crianças não conseguem mais apreender: o indescritível empobrecimento do repertório de imagens, da riqueza de imagines sem a qual elas crescem, o empobrecimento da linguagem e de toda a expressão (ADORNO, 2006, p.146).

0 autor se refere à dificuldade da realização objetiva no âmbito de algumas experiências, como a apreciação da música, utilizada por ele como exemplo. Nesse sentido, deve haver o espaço para o espontâneo, ao mesmo tempo que se desenvolve a consciência, definida como

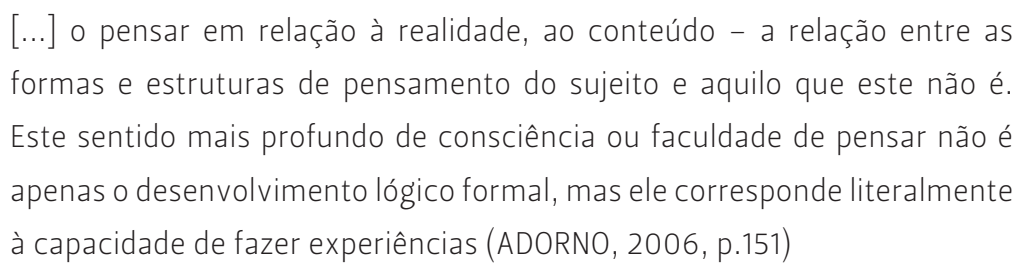

Desse modo, a realização de atividades, por meio de situações que permitam a reflexão acerca da realidade, é profícua para o desenvolvimento da autoconsciência. Destaca-se a espontaneidade como condição para a possibilidade de realização de experiências, nos termos de Giovinazzo Jr. (2012, p.6):

0 que se quer dizer é que a experiência está ligada à espontaneidade. Esta é a possibilidade de os indivíduos lidarem livremente com o mundo a sua volta, que inclui a natureza, a sociedade e os outros indivíduos. Sendo assim, o conceito de experiência com o qual se está lidando aqui supõe atividade e reflexão. A espontaneidade é o momento em que, condicionado 
por certas limitações sociais, o indivíduo busca ir além do que Ihe é oferecido pela existência concreta. Nesses termos, viver experiências implica, mesmo concebendo aquilo que existe a partir de pressupostos, pré-conceitos ou impressões iniciais, não ficar aprisionado a eles. Experimentar é "mergulhar" na objetividade para constituir-se como sujeito.

É importante ressaltar que a noção de experiência aqui tratada está diretamente relacionada à emancipação. Concordando com Adorno, uma educação que vise à emancipação deve ir além da mera adaptação. Se, conforme citado anteriormente, é desde a infância que o indivíduo inicia o processo de formação de uma consciência crítica perante as diversas situações desiguais e desumanas pertencentes à sociedade de base totalitária, então a criança deve viver momentos de livre escolha, de opiniões compartilhadas, do exercício de colocar-se no lugar do outro, de criar, de experimentar e de imaginar.

Ao ser questionado sobre a importância da imaginação para a realização de experiências, Adorno (2006, p.151) conclui:

Todas as iniciativas da chamada reforma educacional realista, por exemplo, de Montessori, no fundo eram hostis em relação à imaginação. Elas conduzem a uma aridez e até mesmo a um emburrecimento a que precisamos nos opor sem que, por outro lado - tudo é complicado -, caiamos nas mentirosas ficções de uma tia dos contos da carochinha.

Dessa perspectiva, não se trata de uma formação escolar nos âmbitos do espontaneísmo, mas de uma formação que possibilite a tomada de consciência, o espaço para o espontâneo e para a imaginação. Vigotsky (1986) apresenta uma perspectiva convergente no livro La imaginación y el arte en la infancia, sobre a importância central do trabalho pedagógico na criação e abertura de espaços para a participação das crianças na cultura. Defende a ampliação da experiência da criança como base para sua atividade criadora, apoiada na imaginação:

De aquí la conclusión pedagógica sobre la necesidad de ampliar la experiência del niño si queremos proporcinarle base suficientemente solida para su atividade creadora. Cuanto más vea, oiga y experimente, cuanto más aprenda y asimile, cuantos más elementos reales disponga en su experiencia, tanto más considerable y productiva será, a igualdad de las restantes circunstancias, la actividad de su imaginación (VIGOTSKY, 1986, p.19). 
Para o autor a imaginação é uma atividade humana que se apoia na experiência e é afetada pela cultura e pela linguagem, carregando marcas da forma racional de pensar, que são historicamente elaboradas. Por sua vez, Walter Benjamin (2002), em suas reflexões sobre a criança e a cultura, aponta para a atividade lúdica como propícia para a realização de experiências. Defende, por exemplo, a ideia de que as crianças construam seus próprios brinquedos, pois é por meio da imaginação e do uso da linguagem simbólica que a criança experimenta outros papéis. Segundo o autor,

Hoje talvez se possa esperar uma superação efetiva daquele equívoco básico que acreditava ser a brincadeira da criança determinada pelo conteúdo imaginário do brinquedo, quando, na verdade, dá-se o contrário. A criança quer puxar alguma coisa e torna-se cavalo, quer brincar com areia e torna-se padeiro, quer esconder-se e torna-se bandido ou guarda. (BENJAMIN, 2002, p.93).

Essa alternância de papéis vividos pela criança, por meio da imaginação e da linguagem simbólica, é de fundamental importância para a constituição de si mesmo, pois também lhe permite experimentar outras possibilidades de ser, o que "fortalece a individuação e a sociedade" (CROCHÍk, 2011, p.34). Portanto, as experiências anteriores são fundamentais para o processo criativo. Reafirma-se, assim, o caráter social da experiência. Retomando as ideias de Vygotsky (1986), a atividade criadora se apoia na experiência, portanto, quanto mais rica é a experiência, mais rica é a sua imaginação e, consequentemente, a apropriação dos elementos da cultura.

Entretanto, para que as experiências vividas pelos indivíduos possam ser expressas, é preciso que o vocabulário seja amplo: "quanto mais uma cultura permite a seus indivíduos se expressarem, mais esses se diferenciam" (CROCHÍk, 2011, p.40). Ainda nas palavras do autor, na nossa cultura, "apesar de ter um acervo linguístico considerável, o restringe ao que pode ser entendido por muitos, reduzindo também a possibilidade de enunciar experiências e, portanto, diferenciar indivíduos" (idem).

Nesse sentido, as experiências vividas são determinantes para, de um lado, o indivíduo refletir consistentemente os padrões da sociedade, o medo, a angústia e a dominação ou, ao contrário, ser livre e autônomo.

A escola, apesar de expressar o todo social, potencialmente pode propiciar a realização de experiências formativas por meio 
da linguagem, se não abrir mão do seu papel, que é o de ensinar mediante a ampliação das possibilidades de experiência da criança.

Portanto, na etapa da Educação Infantil, as atividades devem priorizar o desenvolvimento da linguagem por meio do uso de vocabulário rico, de contato sistemático com situações que não só envolvam o fazer artístico e a apreciação estética, a leitura de imagens, a audição de contos e músicas, a possibilidade de se identificar com personagens e recriá-los a partir das experiências vividas e das especificidades de cada um, como também possam partilhar situações de estranhamento e curiosidade perante o existente. As capacidades e habilidades devem ser estimuladas e nunca negligenciadas com atividades que pouco delas exigem, no que concerne à atividade criadora ou ao manejo das técnicas.

Nesse sentido, o conteúdo das avaliações produzidas pelas escolas pesquisadas ofereceu informações preciosas para 0 entendimento do que é tendencialmente valorizado e transmitido pelas escolas de Educação Infantil em relação às experiências realizadas pelas crianças com a linguagem, que, por sua vez, são mediadas pelas ações e autoridade exercidas pelo professor.

\section{0 material analisado}

Com vistas a analisar como as crianças são avaliadas, a pesquisa foi realizada em duas escolas de Educação Infantil: uma pública, da rede municipal de São Paulo, e uma privada, do mesmo município, assim designadas:

- Escola A- Escola pública da rede municipal de educação de São Paulo;

- Escola B- Escola privada situada no município de São Paulo.

Em ambas selecionou-se o conjunto de avaliações de duas salas de aula de crianças de 5 anos, referentes ao período em que frequentaram a Educação Infantil. ${ }^{3}$ Quanto aos aspectos analisados do conjunto de avaliações, foram destacados excertos sobre linguagem oral e escrita.

Nas escolas pesquisas observou-se uma alternância de instrumentos de avaliação.

3. As escolas pesquisadas disponibilizaram as avaliações de anos anteriores das crianças. 


\section{Os achados da pesquisa: acerca do controle e do empobrecimento da experiência com a linguagem}

Por meio da análise das avaliações das crianças foi possível observar alguns aspectos referentes à experiência das crianças com a linguagem oral e escrita na escola.

De acordo com os dados coletados, um aspecto convergente nas duas escolas - é a realização da escrita espontânea, tal como chamado na escola $A$, e a hipótese de escrita, na escola $B$. Tais propostas consistem na realização de sondagens de escrita em que as crianças devem escrever algumas palavras (seja com base em ilustrações ou ditadas pela professora), cujo objetivo é avaliar em qual fase da escrita a criança se encontra.

Menciona-se como influência decisiva para a avaliação do desenvolvimento da escrita da criança o livro de Emilia Ferreiro e Ana Teberosky, publicado em português com o título A psicogênese da língua escrita (2008), que documenta uma pesquisa experimental, realizada pelas autoras, em Buenos Aires, na década de 1970, cujo objetivo era o de explicar os processos mediante os quais a criança aprende a ler e escrever.

Observou-se, também, a preocupação excessiva com conteúdos relacionados à escrita como: reconhecimento das letras, escrita e leitura do próprio nome, entre outros, conforme os excertos a seguir:

Identificou as letras de seu nome quando contidas em outras palavras, mostrando-se interessado pelo universo letrado e por começar a fazer hipóteses sobre como este sistema funciona. Utilizou as letras convencionais, embora tenha escrito sem fazer os movimentos corretos das mesmas, o que faz parte deste processo de construção.

[Uriel, 4 anos, escola B - turma B1 - $1^{\circ}$ semestre / 2009. Grifo meu]

Interessa-se pelas questões de leitura e escrita, esforçando-se para ler e escrever palavras. Neste semestre, conseguiu registrar o que desejava, atribuindo a cada sílaba o valor sonoro correspondente, chegando a utilizar vogais e consoantes em sua escrita.

[Melina, 5 anos, escola B - turma B1 - 1ºsemestre / 2010. Grifo meu]

Ao escrever, demonstra associar letra ao som, como por exemplo, "OA D OESA" para "RODA DE CONVERSA". O traçado da letra é legível. Nos textos coletivos, contribui somente quando requisitada.

[Fernanda, 4 anos, escola B - turma B2 - $2^{\circ}$ semestre / 2009. Grifo meu] 
$\mathrm{Na}$ sala de aula realiza todas as atividades propostas com pequenas dificuldades. Já consegue traçar algumas letras do próprio nome e algumas vogais com pequenas dificuldades.

[Érica, 4 anos, escola A - turma A2 - $1^{\circ}$ semestre / 2009]

Realiza as atividades propostas com interesse, tenta escrever seu nome e é interessada em aprender letras e números, é muito inteligente e tem muito potencial a ser desenvolvido.

[Larissa, 4 anos, escola A - turma A2 - $1^{0}$ semestre / 2009]

Reconhece o seu nome, as letras A e E.

[Lawany, 4 anos, escola A - turma A2 - 2ºmestre / 2009]

Observa-se, pelos dados coletados nas duas escolas, que a necessidade de controlar a produção das crianças reduz a experiência com a escrita e leitura a aspectos operacionais da avaliação. Nesse sentido, na escola A observa-se a pobreza de estímulos, por meio de atividades repetidas, em que as crianças são habituadas a fazer sempre o mesmo, conforme a sequência de atividades a seguir:
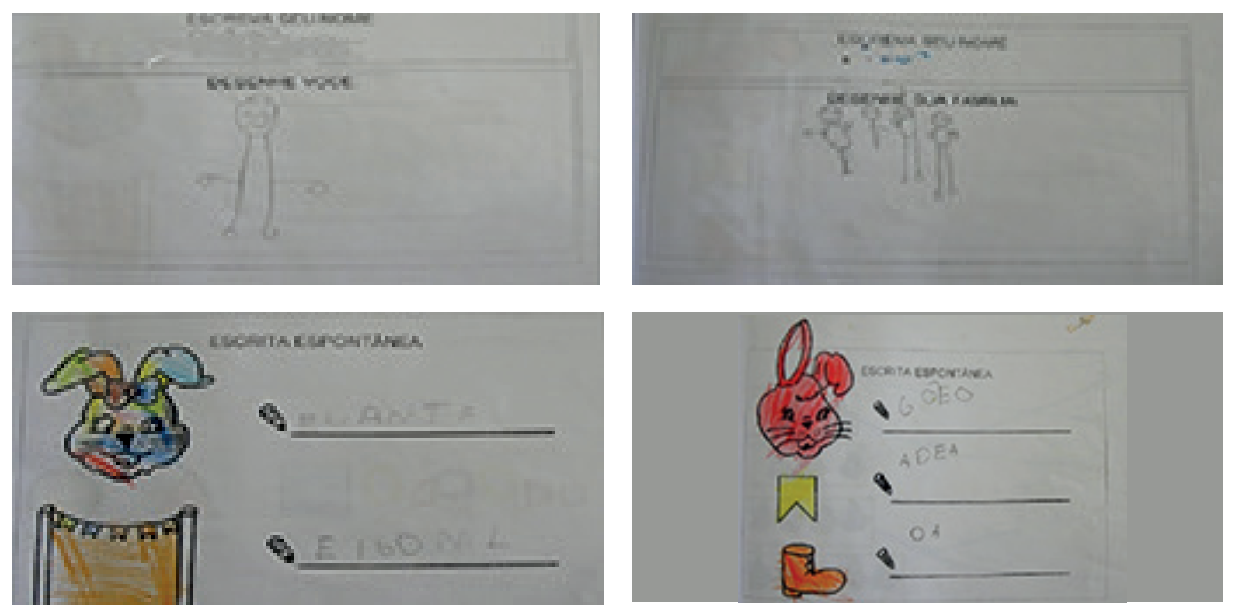

Figura 1- Avaliações diagnósticas -leitura e escrita- [Diego, 5 anos, Escola A]

$\mathrm{Na}$ escola $\mathrm{B}$, apesar da tentativa de apresentar atividades mais cuidadas e dotadas de maior significado para as crianças, a tentativa de controle também se faz presente.

0 quadro a seguir apresenta a síntese dos principais aspectos avaliados nas duas escolas: 


\begin{tabular}{|l|l|l|}
\hline Idade & \multicolumn{1}{|c|}{ Escola A } & \multicolumn{1}{|c|}{ Escola B } \\
\hline 3 & $\begin{array}{l}\text { Escrita do nome, escrita espontânea, } \\
\text { reconhecimento de vogais. }\end{array}$ & $\begin{array}{l}\text { Reconhecimento do próprio nome, leitura } \\
\text { da rotina por meio de imagens, reconhe- } \\
\text { cimento do nome dos colegas com auxílio } \\
\text { da foto. }\end{array}$ \\
\hline 4 & Escrita do nome, escrita espontânea. & $\begin{array}{l}\text { Exploração de letras móveis, escrita do } \\
\text { próprio nome. }\end{array}$ \\
\hline 5 & Escrita do nome, escrita espontânea & $\begin{array}{l}\text { Criação de textos coletivos, escrita de bi- } \\
\text { Ihetes, hipótese de escrita. }\end{array}$ \\
\hline
\end{tabular}

Quadro 1- Conteúdos avaliados em leitura e escrita, nas escolas pesquisadas, de acordo com a idade

Com base nas informações do quadro, observa-se a ênfase a atividades de escrita, o que expressa, em primeiro lugar, uma perspectiva escolarizante da Educação Infantil, com crianças sentadas e escrevendo, em detrimento de propostas lúdicas, cujas situações possuem um fim em si mesmas, como as brincadeiras, audição de histórias, tempo para o ócio, entre outras. Em segundo lugar, a valorização das atividades de escrita, que possuem uma finalidade externa à própria realização da atividade, está em consonância com a sociedade de base capitalista, porque vinculada à ênfase da produção e do resultado. Dessa perspectiva, os indivíduos são controlados pelos processos sociais, baseados na padronização e vinculados a sua utilidade imediata.

\section{Leitura e audição de histórias... Acerca do declínio da narração}

Conforme foi discutido anteriormente, o processo de formação de uma consciência crítica inicia-se na infância. Por meio da participação em diversas situações - tais como a partilha de impressões sobre diferentes assuntos, de alternância de papéis e criação de personagens, entre outros - as crianças podem entrar em contato com os elementos da cultura, reconhecê-los como manifestações sociais, ou estranhá-los, o que permite a contestação do existente.

Nesse sentido, um elemento central, na infância e na Educação Infantil, é a possibilidade de a criança ouvir histórias, a fim de estimular a sua imaginação, a elaboração e a reflexão. Embora as avaliações das duas escolas façam menções a momentos como roda de histórias ou a aspectos sobre interesse em ouvir histórias ou por recontá-las - este último especificamente na escola B -, 
a quase ausência das informações nos documentos expressam o caráter secundário dessa ação nas escolas. Seriam fundamentais, portanto, estudos sobre os momentos de narração de histórias na escola, quais histórias são narradas, as reações das crianças diante do enredo dos contos, bem como a relação dos professores com as narrativas em seu processo de formação.

Em 0 Capital (2004) 4 , no capítulo dedicado às relações entre a maquinaria e a grande indústria, Karl Marx descreve seu objeto de pesquisa, a saber, a fábrica e o conjunto de ações que a transcendem, tais como a maquinaria, legislação, hábitos dos operários e o papel da mulher, do jovem e da criança nesse cenário.

A maquinaria é, segundo o autor, o meio mais poderoso para aumentar a produtividade de trabalho; é o meio mais potente para prolongar a jornada de trabalho, além de todos os limites estabelecidos pela natureza humana (MARX, 2004, p.460). A maquinaria, portanto, é um meio para produzir Mais-valia e, por sua vez, a máquina torna-se uma extensão do homem. Como consequência, a maquinaria aumenta o que o autor chama de material humano explorável pelo capital, apropriando-se do trabalho de crianças e mulheres.

0 autor descreve a jornada de trabalho de crianças na fábrica, nos mais variados ramos, como trabalhar na fundição de cobre, na impressão de jornais, além da mineração e produção de carvão. As crianças cumpriam muitas horas de trabalho em situações degradantes e, em alguns casos, ainda levavam trabalho para suas casas. As más condições de moradia, a falta de higiene das famílias e a exposição a hábitos obscenos, sórdidos e imprudentes, conforme destacados pelo autor, por meio do contato com adultos, configuram o cenário em que as crianças conviviam.

Ora, se outrora as pequenas mãos das crianças eram úteis porque se encaixavam perfeitamente na manipulação de engrenagens menores, as quais as mãos dos adultos não alcançariam facilmente, atualmente, sem considerar as situações degradantes do trabalho infantil que ainda não foi superado, essas mãos pequenas deveriam segurar o lápis e produzir atividades, por vezes, desprovidas de significado. Há, portanto, reduções sucessivas do conhecimento a tarefas estereotipadas.

Em primeiro lugar, conforme observado, as atividades expressam a redução dos elementos do conto a atividades escolares que privilegiam a alfabetização e habilidades motoras.
4. Tomei como referência a $4^{\text {a }}$ parte do $1^{\circ}$ volume, capítulo 13 A maquinaria e a indústria moderna. 
Em segundo lugar, a experiência das crianças com o conto é mediada por ilustrações estereotipadas dos personagens da história, o que retira a possibilidade de cada uma das crianças imaginar seus personagens, o que culmina em uma experiência pobre. Nesse sentido, observa-se, na figura a seguir, a sequência de atividades gráficas cujo tema, conforme as evidências das ilustrações, refere-se à história dos Três Porquinhos:

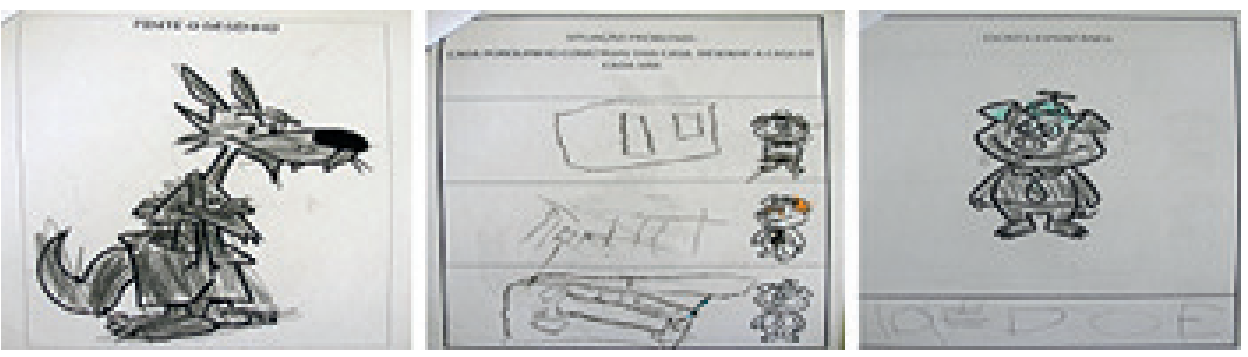

Figura 2- Sequência de atividades baseada na história Os três porquinhos [Diego, 3 anos, Escola A]

Essa redução dos objetos da cultura para finalidades úteis remetem à manutenção da sociedade vigente, visto que não permitem a formação, mas uma pseudoformação. 0 contato com a estereotipia - seja por meio das atividades gráficas da escola ou mesmo pela produção e circulação dos famosos livros de $R \$ 1,99$, pobres do ponto de vista da estética e do enredo, mas voltados para o consumo das massas - elimina o caráter lúdico, o prazer de ouvir histórias como um fim em si mesmo.

Desse modo, parece não haver lugar na escola para a realização de experiências com as narrativas, nem nos termos defendidos por Walter Benjamin, para o qual a noção de experiência está vinculada à tradição e, portanto, as histórias são transmitidas por um narrador por meio da rememoração, tampouco para Adorno, que defende o tempo de ócio para a contemplação e exercício da fantasia e imaginação.

\section{Considerações finais}

Com base na análise dos dados apresentados, constatou-se, por meio das avaliações, o caráter instrumental e padronizado das atividades escolares, com ênfase nos aspectos da alfabetização, em detrimento da possibilidade de um contato lúdico com os livros ou narrações de contos. Além disso, observa-se a imposição do desenvolvimento da criança com base em categorias preestabelecidas e, consequentemente, a subordinação da educação e equalização das práticas escolares aos estágios do desenvolvimento psicológico. 
Observou-se a incidência reduzida de informações sobre a audição de histórias na escola, o que aponta para uma lacuna interessante de pesquisa, sobre os momentos de narração de histórias na escola.

Quanto aos instrumentos avaliativos, observa-se a coexistência de relatórios descritivos, pautas de conduta e atividades diagnósticas, o que aponta para o fato de que, apesar do crescimento de determinações legais e discussões acerca da Educação Infantil, coexistem práticas e ações distintas, sobretudo com ênfase ao preparo para os anos posteriores do processo de escolarização. Em face desse entendimento, é de fundamental importância a compreensão dos modos de efetivação do trabalho pedagógico nessa etapa da Educação.

\section{REFERÊNCIAS}

ADORNO, Theodor W. Educação e emancipação. São Paulo: Paz e Terra, 2006.

CROCHÍK, José Leon. Preconceito e inclusão. WebMosaica. Revista do Instituto Cultural Judaico Marc Chagall, v.3, n.1, jan/jun de 2011.

FERREIRO, Emília; TEBEROSKY, Ana. Psicogênese da Língua Escrita. Porto Alegre: Artmed, 1999.

GIOVINAZZO, Jr. Educação das novas gerações: experiência obstruída e Conformação moral. Anais da $35^{a}$ Reunião Anual da Anped, Porto de Galinhas, 2012. p. 1-15.

MARCUSE. A ideologia da sociedade industrial - 0 homem unidimensional. Rio de Janeiro: Zahar Editores, 1979.

VIGOTSKY, L.S. La imaginación y el arte en la infancia. Madrid: AKAL, 2011.

O desenvolvimento psicológico na infância. São Paulo: Martins Fontes, 2003.

Recebido em: 15/ 10/ 2015.

Revisto em: 3/11/2015.

Aceito em: 07/12/2015.

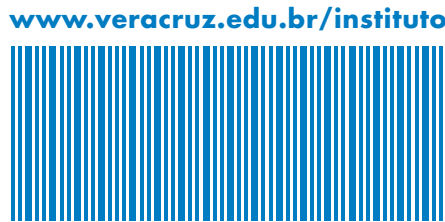

